\title{
Assessment of present awareness on reproductive health and evaluation of a tool designed for reproductive health education among school going adolescent girls
}

\author{
Vanusha A. ${ }^{1 *}$, Parvathavarthini $\mathrm{K}^{2}{ }^{2}$
}

\begin{abstract}
${ }^{1}$ Department of Obstetrics and Gynecology, Saveetha Medical College and Hospital, Chennai, Tamil Nadu, India ${ }^{2}$ Department of Obstetrics and Gynecology, Karpaga Vinayaga Institute of Medical Sciences and Research Centre, Chennai, Tamil Nadu, India
\end{abstract}

Received: 02 April 2018

Accepted: 30 April 2018

\author{
*Correspondence: \\ Dr. Vanusha A., \\ E-mail: doctor.vanusha@gmail.com
}

Copyright: (c) the author(s), publisher and licensee Medip Academy. This is an open-access article distributed under the terms of the Creative Commons Attribution Non-Commercial License, which permits unrestricted non-commercial use, distribution, and reproduction in any medium, provided the original work is properly cited.

\begin{abstract}
Background: Reproductive health is an important area of concern in adolescent health. Assessment of unmet needs of unmarried adolescent girls during past five years revealed the felt needs are mostly unmet in areas related to menstrual hygiene, knowledge on consequences of early marriage, risk of teenage pregnancies, sexually transmitted infections, HIV and AIDS, unsafe abortions and breast feeding. This study is carried out to assess the knowledge of adolescent girls regarding menstruation, pregnancy, contraception, STD's, AIDS, and breast feeding and to study the effect of health education program in terms of improvement in their knowledge.

Methods: This study was carried out among adolescent girls from randomly selected government girls higher secondary schools of Pondicherry from class 8 to class12. A total of 300 students were included in the study. A pretested questionnaire (English/Tamil) was administered to students. This was followed by an interactive session with the students to clarify doubts. Students was asked to fill an immediate post-test questionnaire to evaluate the effect of intervention (health education). After a minimum period of six months the students was reassessed by a same pretest and post-test questionnaire.

Results: There was a statistically significant improvement in knowledge scores in various aspects of reproductive health following periodic health education intervention program.

Conclusions: The knowledge on reproductive health and responsible sexual behaviour among school going adolescents is inadequate. Appropriate strategy to reach this vulnerable group has to be formulated by health care professionals with coordination and support from school authorities.
\end{abstract}

Keywords: Adolescent girls, Health education, Questionnaire, Reproductive health

\section{INTRODUCTION}

WHO defines adolescence as "the period of life between 10 and 19 years of age". ${ }^{1}$ Adolescence represents a window of opportunity to prepare for a healthy adult life. Sound reproductive health is integral to the vision that every child is wanted, every birth is safe, every young person is free from HIV, and every girl and woman is treated with dignity. Reproductive health is an important area of concern in adolescent health. But traditional Indian society regards talks on such topics as taboos and discourages open discussions on reproductive health. ${ }^{2}$ Hence adolescents remain a largely neglected, difficult to measure, and hard to reach population in which the needs 
of adolescent girls in particular are the most ignored. This susceptible group unknowingly enter reproductive duties. The errors committed or omitted in those duties bring about health problems including pregnancy problems and its sequlae and render them infertile or further expand to jeopardize their health and at times lead to death. Reasonable awareness alone can bring about changes in their behaviour and practices.

Among adolescents, the girls are particularly vulnerable for unprotected sex and more susceptible biologically to STDs including HIV. Early childbearing compromises their long term economic potential. In order to lead a healthy, responsible and fulfilling lives and protect themselves from reproductive health problems, adolescent girls need to be knowledgeable about themselves regarding various reproductive health issues because prevention is better than cure. ${ }^{3}$

The importance of educating adolescent girls about their reproductive health is gaining momentum in our country during the past few years. Reproductive health awareness is an important dimension to be integrated into existing sexual and reproductive health programs. Reproductive health awareness is an educational approach which is both relevant and sensitive to many communities' existing sexual and reproductive health needs and concerns.

School approach has been found to be successful in several instances for any behaviour-oriented education, as health and education influence each other. School health education creates awareness among adolescent girls empowering them to take care of their own health as well as protect themselves from possible reproductive health hazards. ${ }^{4,5}$ This study is carried out to assess the knowledge of adolescent girls regarding menstruation, pregnancy, contraception, STD's, AIDS, and breast feeding and to study the effect of health education program in terms of improvement in their knowledge.

\section{METHODS}

It is an intervention study carried out for a period of one year. This Study was carried out among adolescent girls from randomly selected government girls higher secondary schools of Pondicherry. Considering the ability of the school students to respond to a self-administered questionnaire it was decided to include students from class 8 to class 12 .

Considering the feasibility and the beneficial effect of intervention a total of 300 students was included in the study. Group of 30 students per session was found convenient for communication. Verbal consent was obtained from the students to participate in the study after explaining them the objectives of the study. Participation in the study will be voluntary. To ensure that the girls understood the questions, the students was led question by question while answering the questionnaire.

\section{Inclusion criteria}

Adolescent girls from the selected government girls higher secondary school studying from $8^{\text {th }}$ to $12^{\text {th }}$ standard.

\section{Exclusion criteria}

- Absentees

- Students involved in other events of the school who are not able to participate in the study

- Students who are not interested to answer the questionnaire

- $\quad$ Students who are too shy to respond.

\section{Phase 1}

Total of 300 students was encouraged to participate in pretest assessment (A). A pretested questionnaire (English/Tamil) was administered to students in their classroom which includes baseline characteristics of study population, questions related to knowledge on menstruation, menstrual hygiene, pregnancy, antenatal care, contraception, STD's, AIDS. All the questions was explained to the school girls and they were asked to fill it carefully. Then a health education session was presented for these adolescent girls. The session lasted for 30-40 min duration. One session per day covering 30 students was conducted. This was followed by an interactive session with the students to clarify doubts. Students were asked to fill an immediate post-test questionnaire to evaluate the effect of intervention (health education) (B). This exclusive health education program and evaluation was conducted till target of 300 students was achieved.

\section{Phase 2}

After a minimum period of six months the students were reassessed by a same pretest $(\mathrm{C})$, health education and post-test questionnaire (D).

The study protocol and the ethical issues were presented before the Institutional Human Ethics Committee and obtained clearance before the start of the study. Eleven important aspects of reproductive health were included in the study. For questions on knowledge a score of 1 was given for correct answer and a score of zero was given for wrong answer and 'do not know' answer. These scores were added and analysed. Data collected were computed, cleaned and analysed using Microsoft Excel spreadsheet. The data were transformed and statistically analysed using Epidemiological Information Package 2010. The data was analysed using proportions, percentages, frequencies, means, standard deviations. Chi-square test was used to assess the improvement in knowledge. ' $p$ ' values were calculated. Paired ' $t$ ' test was used to test the significance of difference between quantitative variables. A ' $p$ ' value less than 0.05 is taken to denote significant relationship. 


\section{RESULTS}

303 students were enrolled in the study with age group ranging from 12 to 18 years with a mean of 15 years. Randomly selected students from 4 nearby government higher secondary schools from $8^{\text {th }}$ to $12^{\text {th }}$ standard were included. $32.3 \%$ of fathers and $30.4 \%$ of mothers of the participants were illiterate. Only $6 \%$ of parents of participants have studied more than $10^{\text {th }}$ standard. $57 \%$ of parents belong to less than class 4 socioeconomic scale with a mean salary of less than 10000 rupees per month. Drop outs of twenty students were identified after a period of six months (phase 2). Mean age at menarche in the study group was 13.5 years. By the end of phase 2 majority of the girls knew the usual time interval between two menstrual cycles is between 21 days to 35 days. It was observed that there was remarkable improvement in knowledge regarding menstruation and puberty changes following intervention by this study ( $p<0.001$ ). During menstruation, stomach pain, low back pain, headache, malaise were the most common complaints. Having daily bath along with hair washing, frequent change of sanitary napkins were the most common hygienic measures practiced.

Table 1: Scores under each aspect of reproductive health.

\begin{tabular}{|c|c|c|c|c|c|c|c|c|c|c|}
\hline \multirow{3}{*}{ Aspect } & \multirow{3}{*}{$\begin{array}{l}\text { No. of } \\
\text { question }\end{array}$} & \multirow{3}{*}{$\begin{array}{l}\text { Max. } \\
\text { score }\end{array}$} & \multicolumn{8}{|c|}{ Mean score in } \\
\hline & & & \multicolumn{2}{|c|}{ A } & \multicolumn{2}{|l|}{ B } & \multicolumn{2}{|l|}{ C } & \multicolumn{2}{|l|}{ D } \\
\hline & & & Mean & SD & Mean & SD & Mean & SD & Mean & SD \\
\hline Menstruation & 2 & 2 & 1.58 & 0.62 & 1.76 & 0.5 & 1.64 & 0.53 & 1.82 & 0.4 \\
\hline Adolescent health & 6 & 6 & 0.6 & 0.84 & 1.17 & 1.0 & 0.98 & 0.94 & 0.95 & 0.9 \\
\hline $\begin{array}{l}\text { Disadvantages of } \\
\text { early marriage }\end{array}$ & 6 & 6 & 0.45 & 0.52 & 1.41 & 0.94 & 1.03 & 0.8 & 1.83 & 1.12 \\
\hline Age at marriage & 5 & 5 & 2.52 & 0.76 & 3.39 & 0.77 & 2.93 & 0.92 & 3.75 & 0.77 \\
\hline $\begin{array}{l}\text { Effects of population } \\
\text { growth }\end{array}$ & 5 & 5 & 0.99 & 0.88 & 1.88 & 1.31 & 0.72 & 0.81 & 2.1 & 1.01 \\
\hline Pregnancy & 6 & 6 & 2.03 & 1.12 & 3.73 & 0.92 & 3.21 & 1.11 & 4.38 & 0.94 \\
\hline Breastfeeding & 11 & 11 & 2.03 & 1.25 & 3.55 & 1.2 & 2.6 & 1.18 & 4.25 & 1.22 \\
\hline $\begin{array}{l}\text { Unwanted } \\
\text { pregnancy }\end{array}$ & 13 & 13 & 1.77 & 1.22 & 2.97 & 1.41 & 2.13 & 1.32 & 4.1 & 1.52 \\
\hline $\begin{array}{l}\text { Advantages of using } \\
\text { contraception }\end{array}$ & 11 & 11 & 0.07 & 0.31 & 0.43 & 0.59 & 0.3 & 0.52 & 0.79 & 0.69 \\
\hline HIV/AIDS & 18 & 18 & 1.39 & 1.49 & 2.58 & 1.52 & 1.75 & 1.49 & 4.24 & 1.8 \\
\hline STD & 9 & 9 & 0.16 & 0.64 & 0.97 & 0.95 & 0.6 & 0.85 & 1.7 & 1.09 \\
\hline Total score & 92 & 92 & 13.59 & 5.56 & 23.84 & 4.65 & 19.87 & 4.77 & 29.91 & 4.42 \\
\hline
\end{tabular}

During initial pretest majority of the girls were hesitant to answer about the changes they experience during adolescent period. But after the interactive session following the intervention, there was increase in number of girls who answered the question. Among those who answered, students were aware that increase in height, weight and growth of hair in private parts were some of the changes that accompanied puberty.

Most girls intend to seek advice from their mother at the time of having reproductive health problems followed by health care professional and friends. This brings about important issue of feasibility of involving parents in educating their children regarding reproductive health issues. School going girls get most of the information about pubertal changes from their classmates. Hence girls at schools have to be educated about various adolescent and reproductive health problems. When questioned about barriers for seeking help regarding reproductive health problems shy, shame, fear were the causes cited. This being an open-ended question, large number had answered hesitation as one of the reason. Further exploration is needed by rewording the question why they were hesitant to seek help regarding reproductive health issues.

Majority of students knew early marriage has various disadvantages. But very few could point out the reasons. They grossly knew early marriage might to lead to early pregnancy, might endanger mother's life and also affects the health of the child when born to teenage mother. Some had mentioned that early marriage might lead to early drop outs from school and thereby illiteracy might lead to restricted freedom in the in-laws' home.

Two child norms were accepted by most of the students in the 1 st phase of the study with the mean of 1.83. But they had given incongruous answers when questioned about number of children they want. Majority had given male child preference irrespective of total number of children they want. In the $2^{\text {nd }}$ phase of study single child norm was emphasized. Advantages and essentiality of 
single child norm was reinforced. After the intervention more than $50 \%$ of the girls preferred 'single child' family norm. At the start of the study majority of girls indicated 21 to 30 years as the desirable age of marriage for boys and 18 to 25 years as the desirable age of marriage for girls. By the end of the study, majority of the students knew 18 years is the legal age of marriage for girls and 21 years is the legal age of marriage for boys. However, all the girls were of the opinion that age of their marriage lies with their parent's decision. Hence self-decisionmaking attitude has to be inculcated in their minds.

All the students were unanimous in their desire for a gap between the first and second child. But when asked about ideal gap between two children, they had unclear answers. This still states that some were unclear about the essentiality of single child norm even at the end of study. Large majority had realization of negative impact of uncontrolled population growth on development of the country. Economic burden, Intra familial issues, Depletion of natural resources, pollution were the most common adverse effects cited by students. Knowledge on other aspects like poor sanitation, spread of infectious diseases, shortage of electricity, increase in crime rate was poor. But however, there was a statistically significant improvement in knowledge regarding adverse effects of uncontrolled growth population by the end of the study.

Table 2: Scores under all aspects of reproductive health (total score) impact of intervention.

\begin{tabular}{|llll|}
\hline Score at & \multicolumn{3}{l}{$\begin{array}{l}\text { Knowledge scores on all aspects of } \\
\text { reproductive health }\end{array}$} \\
& Range & Mean & SD \\
\hline A & $4-30$ & 13.59 & 5.56 \\
\hline B & $13-40$ & 23.84 & 4.65 \\
\hline C & $7-32$ & 17.87 & 4.77 \\
\hline D & $15-46$ & 29.91 & 4.42 \\
\hline 'p' value between & \\
\hline A and B & $<0.001$ Significant \\
\hline B and C & $<0.001$ Significant \\
\hline A and C & $<0.001$ Significant \\
\hline A and D & $<0.001$ Significant \\
\hline No. of questions: 92; Maximum score: 92 \\
\hline
\end{tabular}

Regarding question of how conception takes place, many students had answered having sex, that is union of male and female body, kissing, touching would result in conception. It has to be made clear that following sexual intercourse, it is the union of sperm and ovum that results in conception. Hence propagation of safe sex methods has to be emphasized in future studies.

It was heartening to note after $2^{\text {nd }}$ phase of study, large number of girls gained knowledge regarding missing periods as the first sign of pregnancy, importance of child spacing, minimal number of medical checkups needed during pregnancy. However, need for extra food, immunization during pregnancy, role of contraceptive in child spacing should furthermore be emphasized.

In the initial pre-test, students were not aware of when the new-born should be first breastfed and for how long. But by end of $2^{\text {nd }}$ phase of study, there was statistically significant improvement in knowledge scores on questions regarding breast feeding. They had answered breast feeding will help in growth of new-born, will increase the immune power, will ensure bonding between mother and child.

Majority of students had answered having boyfriend, having illegal contact with boyfriend without parent's knowledge will result in unwanted pregnancy. But during $2^{\text {nd }}$ phase of the study, it was emphasized inadequate knowledge/failure/improper use of contraceptives will result in unwanted pregnancy. In case, if future studies are conducted, much more importance should be given to this aspect of reproductive health problem.

During the initial phase of study less than $4 \%$ of the students had heard of any family planning methods. Even by end of $2^{\text {nd }}$ phase of study, it was difficult for the students to understand the uses of contraceptives. Only the names were made familiar to them. Though there was statistically significant improvement in knowledge at the end of the study repeated reinforcement had to be done in this area for sustained knowledge.

While asking students whether they would use contraceptives in future they answered affirmatively. But it should be noted that still in India decision making power about conception and contraception lies with husband and in laws.

Very few had heard about STD during initial pretest. By the end of study, symptoms, mode of spread, methods of prevention were made familiar to them.

\section{DISCUSSION}

This study was carried out to assess the current knowledge and attitude about reproductive health among school going adolescent girls and to determine the short term and long-term efficacy of a health education intervention program in improving their knowledge and attitude about reproductive health.

The mean age of menarche was 13.5 years which was comparable with studies conducted by Singh MM et al and Mittal et al. ${ }^{6,7}$ The mean age of respondents were 15 years. During the initial pretest, gross inadequacy in knowledge was found. This was consistent with various other studies conducted on reproductive health. ${ }^{8-11}$ The problem of dysmennorhea reported in the present study $(65 \%)$ was higher than that reported from rural Nagpur $(20.4 \%)$ but was comparable to $57 \%, 61 \%, 64 \%$ prevalence found in Mumbai, Chennai, East Delhi respectively. ${ }^{12-15}$ 
Three different studies have reported that $80 \%$ of girls in rural areas of East Delhi, Guntur and Vadodara district were forbidden from worshipping and had restrictions on many day to day activities during menstruation. ${ }^{15-17}$ However girls in the present study group had given least priority to these findings. Differing observations may be accounted for due to regional variations in views and attitude.

\section{Adolescent health}

In present study most of the girls intend to seek advice from their mother $(75 \%)$ regarding reproductive health issues which is in contrast with the study conducted by MM singh et al, and Mittal et al. ${ }^{6,7}$ Where about $49.2 \%$ and $47.4 \%$ of girls seek advice from mother respectively. In study conducted by Kotecha et al and Ahuja and Tiwari school going girls get most of the information about pubertal changes from their classmates and mass media respectively. ${ }^{17,18}$ While Francis et al quoted that frequent source of information about reproductive facts were from books $(53.8 \%) .{ }^{19}$

In present study an attempt was made to know from students, what are the barriers for seeking help regarding reproductive health problems. Future studies had to focus on alleying these barriers so that it will help students to freely discuss their problems with health care professionals.

\section{Age at marriage}

In the present study, student had mentioned the desirable age for marriage of girls as 18 to 25 years and 21 to 30 years for boys. $75 \%$ of students accepted two child norm with greater than $75 \%$ wants at least one male child. This is in contrast with the study conducted by Benjamin et al, where desirable age for marriage of girls was 21 to 25 years and that for boys was 20 to 25 years. ${ }^{20}$ In their study ,2 child norm was acceptable to most with one son and one daughter. ${ }^{2,8,20}$ Theirs was a descriptive study where lacuna in knowledge of respondents were identified. But the present study analysed the lacuna and after 2 phases of health education program 1 child norm was acceptable to more than $50 \%$ at the end of the study.

\section{Uncontrolled growth population}

Large majority of students in the present study had realization of negative impact of uncontrolled population growth on the development of the country. Shortage of food, air, water, agriculture land and lack of employment facilities were the main concern. These results were comparable with the study conducted by Benjamin et al. ${ }^{20}$

\section{Pregnancy}

In the present study $51 \%$ of girls answered nausea and vomiting followed by $32 \%$ of girls answered missing periods as the first sign of pregnancy during initial phase of the study. However following health education, $82 \%$ of the girls were aware that missing period is the first sign of pregnancy which is comparable to the intervention study conducted by Rao et al. ${ }^{21}$ This is significantly higher than study conducted by Malleshappa et al where only $74 \%$ had answered correctly following intervention. ${ }^{22}$ In a study report published by voluntary health association in rural Orissa, only $37 \%$ had correctly identified stopping of monthly cycle as the sign where one should suspect pregnancy. ${ }^{3}$

Fallopian tube as the site of fertilization and uterus as the site of implantation of embryo was made familiar to the students in the present study. However inadequate knowledge about understanding of reproductive system was found among students. ${ }^{15}$

Importance of minimum health check-ups needed during pregnancy, interval period for child spacing between births like many other studies were emphasized in the present study. ${ }^{2.6 .20}$

\section{Breast feeding}

In the present study by the end of phase 2, $81 \%$ were aware that new-born should be first breastfed within 30 minutes of birth. $70 \%$ were aware that new born should be exclusively breastfed for 6 months. This was a statistically significant improvement in knowledge following our health education intervention program.

\section{Contraception}

In the present study only $2 \%$ of the girls were aware of condom and copper $\mathrm{T}$ during the initial phase. This was very less when compared to study by Gupta $\mathrm{N}$ and Malleshappa et al where $20 \%$ and $37 \%$ respectively were aware of at least one method of contraception. ${ }^{8,22}$ Only $2 \%$ quoted population control and child spacing as advantages of contraceptives. However statistically significant improvement in knowledge regarding contraceptives were found following health education.

The present study indicates that the adolescent girls are still ignorant on various contraceptive methods, their sources and their uses. This concurs with the findings of some other Indian studies. ${ }^{8,21,23-25}$

\section{HIVIAIDS and STD}

In the present study almost all the girls had heard about HIV/AIDS. Only 5\% of the students were able to expand HIV/AIDS. $17.5 \%$ were aware that HIV spreads through unsafe contact. Rest of them had unclear knowledge. Majority of them were unaware about other modes of transmission of AIDS. Some had thought HIV is a communicable disease and can be cured by taking medicines. None were aware of the availability of antiretro viral drugs. Less than $1 \%$ of the girls had heard of STD, its clinical symptoms, modes of transmission and 
methods of prevention. These figures are very low when compared with the studies conducted in East Delhi where $50 \%$ were able to expand HIV/AIDS. And $50 \%$ of girls were able to mention sexual route and sharing syringes and needles as modes of transmission of HIV/AIDS. ${ }^{11}$

The present study indicates that adolescent girls in Pondicherry are ignorant on this aspect of reproductive health. This concurs with the findings of other Indian studies. ${ }^{2,6}$ Hence there is a need for re-enforcing school AIDS education.

The present study however concludes that the Health education intervention program by health care professionals at periodic intervals will help in bringing about statistically significant improvement in knowledge on reproductive health issues. Various studies concurs with this finding. $4,8,21,26$

\section{CONCLUSION}

The knowledge on reproductive health and responsible sexual behaviour among school going adolescent girls is inadequate. Periodic health education program is effective in improving the knowledge and attitude of adolescents in these issues. The findings of this study can be useful in planning future research and programming initially in a small Union Territory of Pondicherry and depending upon its success can be extrapolated to other bigger states in its local vernacular. Appropriate strategy for reaching this vulnerable group seems to be mainly through schools by the health care professionals (Health Department) with the active support and coordination by the school authorities (Education Department).

The unmet sector in adolescent health is identified as lack of awareness. The aspect of increasing the level of awareness and thereby reducing the level of ignorance by health education programs should be taken care by government and non-governmental organizations.

- This reproductive health education programs should not only be made available to girls but also to adolescent boys.

- Pregnancy prevention programs must address the role of young men.

- Intervention to improve the status of adolescent girls should aim to impact upon the decision-making powers of adolescent girls regarding reproductive and sexual health by increasing the level of awareness.

- Health Department and Education Department professionals should organize educative sessions for parents, so that they can understand reproductive health problems and know conditions for which their adolescent children can report to the health professionals.

- Increasing premarital sexual activity, problems of unsafe abortions and teenage pregnancies should be given more importance by conducting direct and specific studies.

- Attitude towards contraceptive use and also knowledge about HIV/AIDS and STD must be imparted for inducing preventive behavior

- Incorporation of structured teaching program on reproductive health in the school curriculum is recommended

- Promotion of contraceptives, problems of unsafe abortion and teenage pregnancies through mass media (similar to 'alcohol and smoking is injurious to health') will definitely have a positive impact on adolescent girls, boys and their parents.

Funding: No funding sources

Conflict of interest: None declared

Ethical approval: The study was approved by the Institutional Ethics Committee

\section{REFERENCES}

1. Orissa Voluntary Health Association. Sexual health status of adolescent girls in rural Orissa: Study report conducted by Orissa Voluntary Health Association; 2001-2002.

2. World Health Organization. "Coming of Age" from facts to action for adolescent sexual and reproductive health. WHO Geneva. 1997:4. Available at http://www.who.int/iris/handle/10665/65895

3. INCLEN. International Clinic Epidemiology Network. 1998-2001. Available at www.inclen.org.

4. Devi DK. A study on menstrual hygiene among rural adolescent girls. Indian J Med Sci. 1994;48:139-43.

5. Adolescence: Development and Obstacles. Adolescence, Resource and Reference Centre, Psychosocial aspects of AIDS CMC Vellore. Health Dialogue. 2002;28:1-3..

6. Parwej S, Kumar R. Reproductive health education intervention trial. Indian J Paediatr. 2005;72:287-91.

7. NIPCCD. Studies on adolescent girls: an analytical review. Published by National Institute of Public Cooperation and Child Development. 2008. Available at http://nipccd.nic.in/reports/eag.pdf

8. Singh MM, Devi R, Gupta S. Awareness and health seeking behavior of rural adolescent school girls on menstrual and reproductive health problems. Indian J Med Sci. 1999;53:439-43.

9. Mittal K, Goel MK. Knowledge regarding reproductive health among urban adolescent girls of Haryana. Indian J Community Med. 2010;35:529-30.

10. Gupta N, Mathur AK. Reproductive health awareness of school going, unmarried rural adolescence. Indian J Paediatr. 2004;71:797-801.

11. Roy S. Education of adolescents on reproductive health: which way to go? J Nepal Med Assoc. 2010;49(177):88-91.

12. Mishra BS. A study of the improvement of population awareness among the senior school 
students through exposure to population. Researches in Population Education. 2000:94.

13. Lal P, Anitha NA. Study of awareness about HIV/AIDS among senior secondary school children, Delhi. Indian J Community Med. 2008;33:190-2.

14. Durge PM, Waradpande U. Impact of assessment of health education in adolescent girls. J Obst Gyn 1995;41:46-50.

15. Gandhi AB, Raval. The role of audio visual programme in creating awareness about reproductive health in adolescent girls. J Obstet Gynaecol India 1993;43:257-61.

16. Shiela, Malathy. Menstrual and gynecological disorders in 500 school girls in Madras city. J Obstet Gynaecol India. 1993;43:940-5.

17. Nair P, Grover. Awareness and practices of menstruation and pubertal changes amongst unmarried female adolescents in a rural area of East Delhi. Indian J Community Med. 2007;32:156-7.

18. Devi DK. A study on menstrual hygiene among rural adolescent girls. Indian J Med Sci. 1994;48:139-43.

19. Kotecha PV, Patel S. Reproductive health awareness among rural school going adolescents of Vadodara district. Indian J Sex Transm Dis. 2009;30:94-9.

20. Ahuja A, Tewari S. Awareness of pubertal changes among adolescent girls. J Fam Welfare. 1995;41:4650 .

21. Francis PT, Gill JS. Knowledge, beliefs and attitudes regarding AIDS, STDs and human sexuality among senior secondary students in Delhi. Indian J Comm Med. 1994;39:17-20.

22. Benjamin, Panda P, Singh S, Bhatia AS. Knowledge and attitude of senior secondary school students of
Ludhiana regarding population control and contraception. Indian J Comm Med. 2001;26(4):201.

23. Rao R, Lena A, Nair NS. Effectiveness of reproductive health education among rural adolescent girls: a school-based intervention study in Udipi Taluk, Karnataka. Indian J Med Sci. 2008;62:439-43.

24. Malleshappa, Shivaram K. Knowledge and attitude about reproductive health among rural adolescent girls in Kuppam Mandal: an intervention study. Biomed Res. 2011,22(3)

25. Government of India Ministry of Health and Family Welfare. Statewise HIV prevalence (1998-2004). Available at www.nacoonline.org.

26. Kumar R, Agarwal AK. Adolescent behavior regarding reproductive health. Indian $\mathrm{J}$ Pediatr. 2000;67:877-82.

27. Bhatia V. Fertility control methods: Knowledge of adolescent girls in schools of Chandigarh. Ind J Med Sci. 2000;54:342-6.

28. Dhittal AD, Badhu BP. Effectiveness of structured teaching program in improving knowledge and attitude of school going adolescent girls on reproductive health. Kathmandu University Med J. 2005;3:380-3.

Cite this article as: Vanusha A, Parvathavarthini K. Assessment of present awareness on reproductive health and evaluation of a tool designed for reproductive health education among school going adolescent girls. Int J Reprod Contracept Obstet Gynecol 2018;7:2381-7. 